\title{
A Systematic Review and Meta-Analysis on the Efficacy of Repeated Transcranial Direct Current Stimulation for Migraine
}

\author{
Guoshuai Cai ${ }^{1, *}$ \\ Zhu Xia ${ }^{2, *}$ \\ Leigh Charvet ${ }^{3}$ \\ Feifei $\mathrm{Xiao}^{4}$ \\ Abhishek Datta ${ }^{5,6}$ \\ X Michelle Androulakis (iD) $7,8, *$ \\ 'Department of Environmental Health \\ Sciences, Arnold School of Public Health, \\ University of South Carolina, Columbia, \\ SC, 29208, USA; ${ }^{2}$ Department of \\ Epidemiology, School of Public Health, \\ Nanjing Medical University, Nanjing, \\ 2III66, People's Republic of China; \\ ${ }^{3}$ Department of Neurology, NYU \\ Grossman School of Medicine, New York \\ City, NY, USA; ${ }^{4}$ Department of \\ Epidemiology and Biostatistics, Arnold \\ School of Public Health, University of \\ South Carolina, Columbia, SC, 29208, \\ USA; ${ }^{5}$ Research and Development, \\ Soterix Medical, New York, NY, USA; \\ ${ }^{6}$ Department of Biomedical Engineering, \\ City College of New York, New York, \\ NY, USA; ${ }^{7}$ Neurology, Columbia VA \\ Health System, Columbia, SC, USA; \\ ${ }^{8}$ School of Medicine, University of South \\ Carolina, Columbia, SC, USA
}

*These authors contributed equally to this work
Correspondence: X Michelle Androulakis Columbia VA Health System, 6439 Garners Ferry Road, Columbia, SC, 29209, USA

Email Xiao.androulakis@va.gov
Purpose: Transcranial direct current stimulation (tDCS) may have therapeutic potential in the management of migraine. However, studies to date have yielded conflicting results. We reviewed studies using repeated tDCS for longer than 4 weeks in migraine treatment, and performed meta-analysis on the efficacy of tDCS in migraine.

Methods: In this meta-analysis, we included the common outcome measurements reported across randomized controlled trials (RCTs). Subgroup analysis was performed at different post-treatment endpoints, and with different stimulation intensities and polarities.

Results: Five RCTs were included in the quantitative meta-analysis with a total of 104 migraine patients. We found a significant reduction of migraine pain intensity (MD: -1.44 ; CI: $[-2.13,-0.76])$ in active vs sham tDCS treated patients. Within active treatment groups, pain intensity and duration were significantly improved from baseline after tDCS treatment (intensity MD: -1.86 ; CI: [-3.30, -0.43$]$; duration MD: -4.42 ; CI: $[-8.11,-0.74]$ ) and during a follow-up period (intensity MD: -1.52 ; CI: $[-1.84,-1.20]$; duration MD: -1.94 ; CI: $[-3.10,-0.77])$. There was a significant reduction of pain intensity by both anodal (MD: -1.74 ; CI: $[-2.80,-0.68]$ ) and cathodal (MD: -1.49 ; CI: $[-1.89,-1.09])$ stimulation conditions.

Conclusion: tDCS treatment repeated over days for a period of 4 weeks or more is effective in reducing migraine pain intensity and duration of migraine episode. The benefit of tDCS can persist for at least 4 weeks after the completion of last tDCS session. Both anodal and cathodal stimulation are effective for reducing migraine pain intensity.

Keywords: transcranial direct current stimulation (tDCS), neuromodulation, migraine, metaanalysis

\section{Introduction}

Migraine is one of the most common neurological disorders associated with significant disability. ${ }^{1,2}$ The global prevalence of migraine was estimated at $14.7 \%$ (around 1 in 7 people). ${ }^{3}$ Defined as a primary headache disorder with repeated episodic flare up lasting 4-72 hours, characteristic migraine headache has moderate to severe head pain intensity, unilateral location and throbbing/ pulsating pain quality, associated with photophobia, nausea and/or vomiting. ${ }^{4}$

The exact pathophysiology of migraine is still unknown and is thought to involve both central and peripheral nervous systems. ${ }^{5}$ Current advances in migraine research suggest that calcitonin gene-related peptide (CGRP) plays a significant role in the activation of trigeminal vascular pathway that is sufficient to trigger a 
cascade of downstream effect of neurogenic inflammation, mast cell degranulation and vasodilatation. ${ }^{6}$ Even though CGRP receptor antagonists have emerged as a promising therapeutic opportunity for the management of migraine ${ }^{7}$ along with other pharmaceutical treatments such as ergots, triptans, 5-HT $1 \mathrm{~F}$ receptor agonist, these are generally of moderate efficacy but may have low tolerability due to adverse effects such as gastrointestinal disturbances, memory and concentration problems, fatigue, and nausea. ${ }^{8}$ Therefore, there is an unmet clinical need for using novel non-pharmacological interventions for this debilitating primary headache disorder.

Non-invasive brain stimulation (NIBS) has emerged as a promising therapeutic option for migraine management due to its potential ability to induce changes in brain plasticity. ${ }^{9}$ NIBS includes but is not limited to transcranial magnetic stimulation (TMS), transcranial electrical stimulation such as transcranial direct current stimulation (tDCS) and transcranial alternating current stimulation (tACS), transcutaneous auricular vagus nerve stimulation, peripheral nerve stimulation (vagus nerve, trigeminal nerve, supraorbital nerve, occipital nerve), pulsed radio frequency, transcranial near-infrared stimulation (NIRS) and electro acupuncture. So far, only single pulse TMS, vagus nerve stimulation (VNS), and supraorbital neurostimulation have been approved by FDA for migraine.

Widely investigated across a range of therapeutic applications, tDCS has advantages of low cost, device portability for potential home use, well-established safety and tolerability. Depending on the montage configurations, the electrical field generated via tDCS generally spreads to nearby cortical and subcortical structures. ${ }^{10}$ Duration of electrical changes is typically maintained only for an hour locally after one time tDCS treatment, ${ }^{11}$ while sustained and repeated tDCS sessions can provoke cumulative and long-lasting neuroplastic changes in the cerebral cortex. ${ }^{12}$ Even though the majority of current clinical trials using tDCS for a variety of neurological disorders have been limited by the number of sessions (many studies report findings after 10 or less daily sessions), those that have used extended designs have demonstrated cumulative behavioral ${ }^{13,14}$ and motor ${ }^{15}$ effects.

A systematic review and meta-analysis in $2016^{16}$ suggested that tDCS could be a promising non-pharmaceutical alternative for migraine. Another meta-analysis in $2019^{17}$ evaluated the effect of both TMS and tDCS for migraine treatment, and found that the excitatory stimulation of primary motor cortex (M1) may reduce the intensity and frequency of headache in migraine patients. ${ }^{17}$ However, these studies did not focus on repetitive tDCS treatment of at least 4 weeks. Recently published studies used different tDCS sessions for migraine yield inconsistent results, which may be partially associated with insufficient treatment as repetitive tDCS stimulation may enhance brain plasticity via long-term potentiation (excitatory) or longterm depression (inhibitory). ${ }^{18}$

There is a paucity of comprehensive analysis on repetitive tDCS treatment results and whether tDCS has longterm effects on migraine. Furthermore, subgroup analysis to compare specific stimulation polarity (anodal and cathodal) is needed. The aim of this review was to summarize and critically evaluate human studies examining the efficacy of repetitive tDCS for at least 4 weeks for management of migraine. Additionally, we provided suggestions to facilitate tDCS clinical trials for migraine in the future.

\section{Methods}

\section{Literature Search}

Literature search was conducted in three databases including PubMed, EMBASE and Web of Science from the date of first available article up to December 2019. We identified studies related to tDCS and migraine using keywords "tDCS" or "Transcranial Direct Current Stimulation" for tDCS and "Migraine", "Migraine Disorders", "Migraine Headache", "Migraine with Aura", "Migraine without Aura" or "Chronic Migraine" for migraine. No other filters were used. We applied the principles of the Preferred Reporting Items for Systematic Reviews and MetaAnalyses (PRISMA) statement ${ }^{19}$ to further screen and filter studies.

Two reviewers independently screened studies to determine whether they meet the eligibility criteria shown below. To solve the differences, reviewers negotiated together or consulted with the third reviewer. Then, the full text of all potentially relevant studies was analyzed to verify compliance with eligibility criteria and whether the results were adequately reported.

\section{Eligibility Criteria}

We followed the $\operatorname{PICOS}^{20}$ (Participants, Intervention, Comparators/Controls, Outcomes, Study types) framework to organize the inclusion criteria. Participants (P): adults 18-65 years old with migraine including migraine with/ without aura and chronic migraine; Interventions (I): transcranial direct current stimulation (tDCS); Comparators/ 
Controls (C): sham stimulation treatment; Outcomes $(\mathrm{O})$ : outcomes related to headache intensity, duration of each headache episode, migraine frequency, number of headache attacks and use of pain medication; and Study types (S): randomized controlled trials (RCTs).

We excluded studies that did not used randomized controlled designs as well as those that: (1) administered fewer than 145 repetitive tDCS stimulation sessions (i.e., less than 4 weeks of treatment); (2) used other types of electrical stimulation instead of sham for control comparison; (2) included subjects with headache disorders other than migraine; (3) were published in the form of reviews, conference abstract/posters, editorials, or consensus guidelines; and/or (4) provided insufficient data for analyses (such as raw data, means or p-values only).

\section{Risk of Bias Assessment}

Two researchers independently assess risk of bias of each study. Discrepancies were resolved by a third researcher. The following criteria were considered to assess the risk of bias in our analysis: sequence generation (selection bias), allocation sequence concealment (selection bias), blinding of participants and personnel (performance bias), blinding of outcome assessment (detection bias), incomplete outcome data (attrition bias), selective outcome reporting (reporting bias), and other potential sources of bias. ${ }^{21}$ The RevMan 5.3 software was applied to assess and visualize such Cochrane risk of bias.

\section{Data Extraction and Data Items}

Data were extracted by the same researcher from each article and included the following items: study design (type, randomization, and blinding), participants in each group, stimulation protocols (montage-stimulation electrode and reference electrode, electrode size, current intensity and duration), outcome measurements, and results. Outcomes included head pain intensity (scaled from 0 to 10 monthly) and duration of each migraine episode (hours per migraine per month). We also reviewed studies on migraine frequency (migraine-related days per month), number of migraine attacks (monthly average), and use of pain medications (monthly average). However, only very few studies reported these outcomes and therefore we did not perform meta-analysis.

\section{Data Analysis}

For the meta-analysis, we processed data at three phases (before stimulation, after the last stimulation and in the follow-up phase). Two outcome measurements were investigated: pain intensity and duration of each migraine episode. Based on the central limit theorem, we assumed the difference of means of samples in comparison is normally distributed, thus we can calculate mean difference (MD) and $95 \%$ confidence interval (CI) from the standard normal distribution with mean and standard deviation or $\mathrm{p}$ value estimated in each study. Upon availability, either mean or median difference were considered as good estimator of population mean difference. Studies used two different scale ranges for pain intensity, either with a 0-3 or $0-10$ score range. Therefore, for uniform comparison, we normalized the pain intensity measurement to a $0-10$ score scale for all studies by min-max normalization.

To evaluate the efficacy of tDCS treatment, we performed between-group and within-group analyses. For between-group analysis (active versus sham), we compared the change of each outcome measurement in tDCS treatment group with that in sham group. The mean change was calculated by comparing the mean measurement after treatment with that before treatment. For within-group analysis, we compared the changes in outcome measures after the intervention within the tDCS treatment group and the sham group (if available) separately. In each group, the mean effect showing after treatment was assessed by the change of measurement after last stimulation from baseline, and the long-term effect was assessed by the change of measurement at the follow-up endpoint from baseline. Using the same analysis approach, we further conducted a subgroup comparison to evaluate the effects of stimulation polarity (anodal versus cathodal). To account for the heterogeneity, all pooled effects were estimated from metaanalysis using random-effects models.

We used R (v.3.6.3) software for data processing and obtained summary statistics including the mean and the $95 \%$ confidence interval of difference. With the summary statistics, meta-analysis was performed using the Comprehensive Meta-Analysis (CMA) V3 software (Biostat, NJ, USA). We also evaluated the impact of each study on the overall effect size by sensitivity analysis using the one-study remove (leave-one-out) approach. ${ }^{22}$

\section{Results}

\section{Selection and Characteristics of Studies, and Bias Risks Assessment}

According to the search criteria, our preliminary search yielded 267 results in which 155 non-duplicated studies 
were identified. Removing irrelevant and incomplete articles such as meeting abstracts and posters, 84 articles were left for rigorous screening of eligibility. Finally, a total of 5 eligible studies were included for meta-analysis. The detailed procedure for the study selection and exclusion is shown in Figure 1. Data from a total of 104 migraine patients receiving either active or sham tDCS were used to evaluate of the effects of tDCS on migraine pain intensity and duration of each migraine episode. We provided the summary of these studies in Table 1.
We evaluated possible risks of bias for each individual study according to the Cochrane handbook ${ }^{22}$ and summarized in Figure 2. Three studies ${ }^{23-25}$ shown potential risks of selection bias, including two studies did not specify or mention the methods used for randomization and hidden allocation $^{23,25}$ and one study performed random sequence generation by using the patient order of entrance in the study. ${ }^{24}$ Except for Rocha's study, ${ }^{26}$ which had a high rate of loss to follow-up, all studies were considered to have a lower risk of attrition bias.
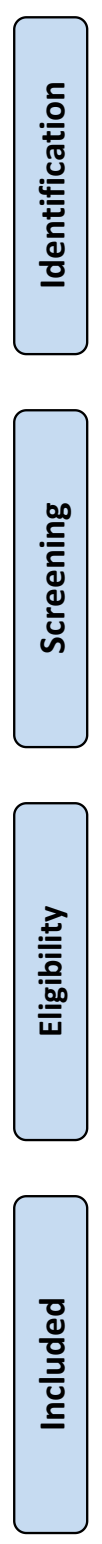

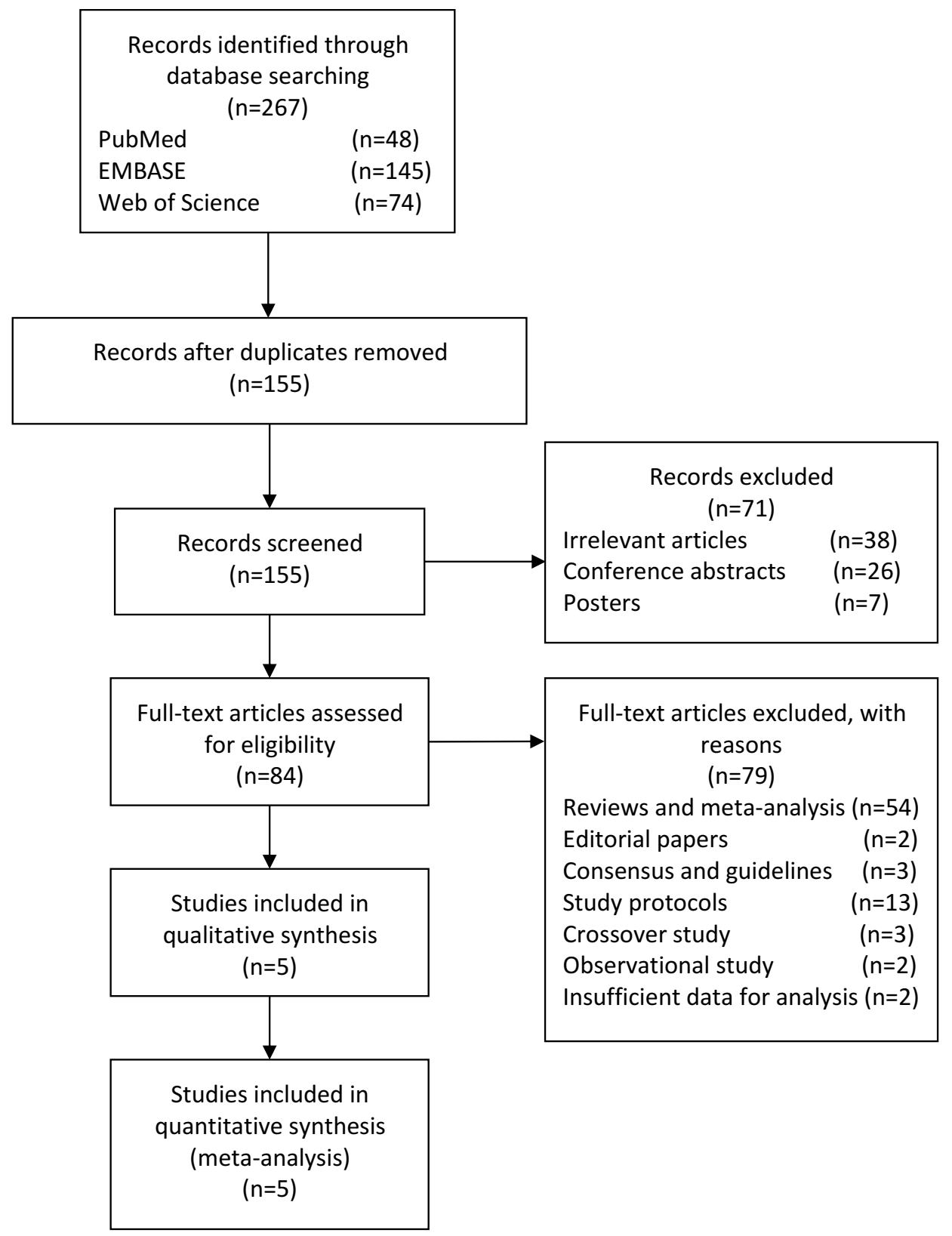

Figure I PRISMA flow diagram for study selection.

Notes: Adapted from Moher D, Liberati A, Tetzlaff J, Altman DG, The PRISMA Group (2009). Preferred Reporting Items for Systematic Reviews and Meta-Analyses: The PRISMA Statement. PLoS Med 6(7): el 000097. ${ }^{19}$ 


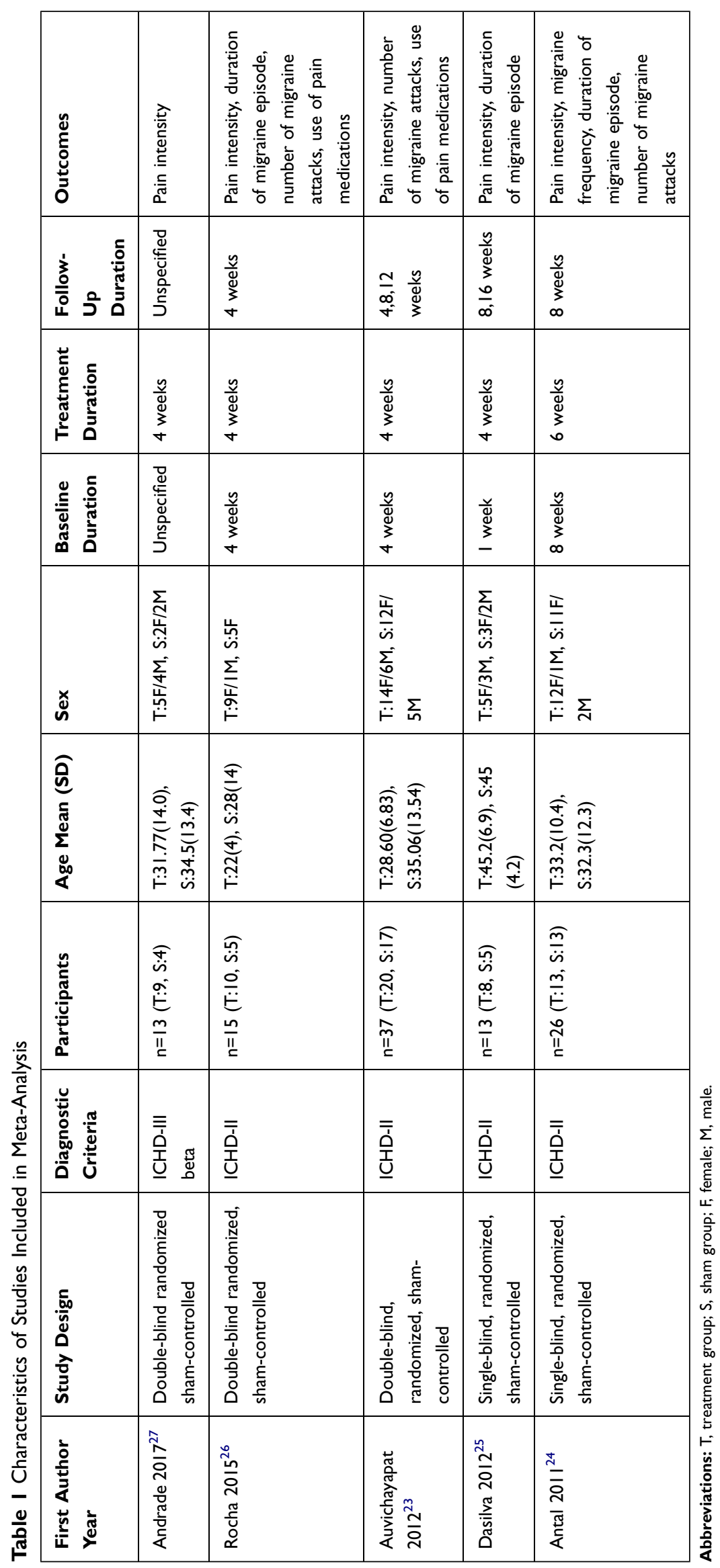




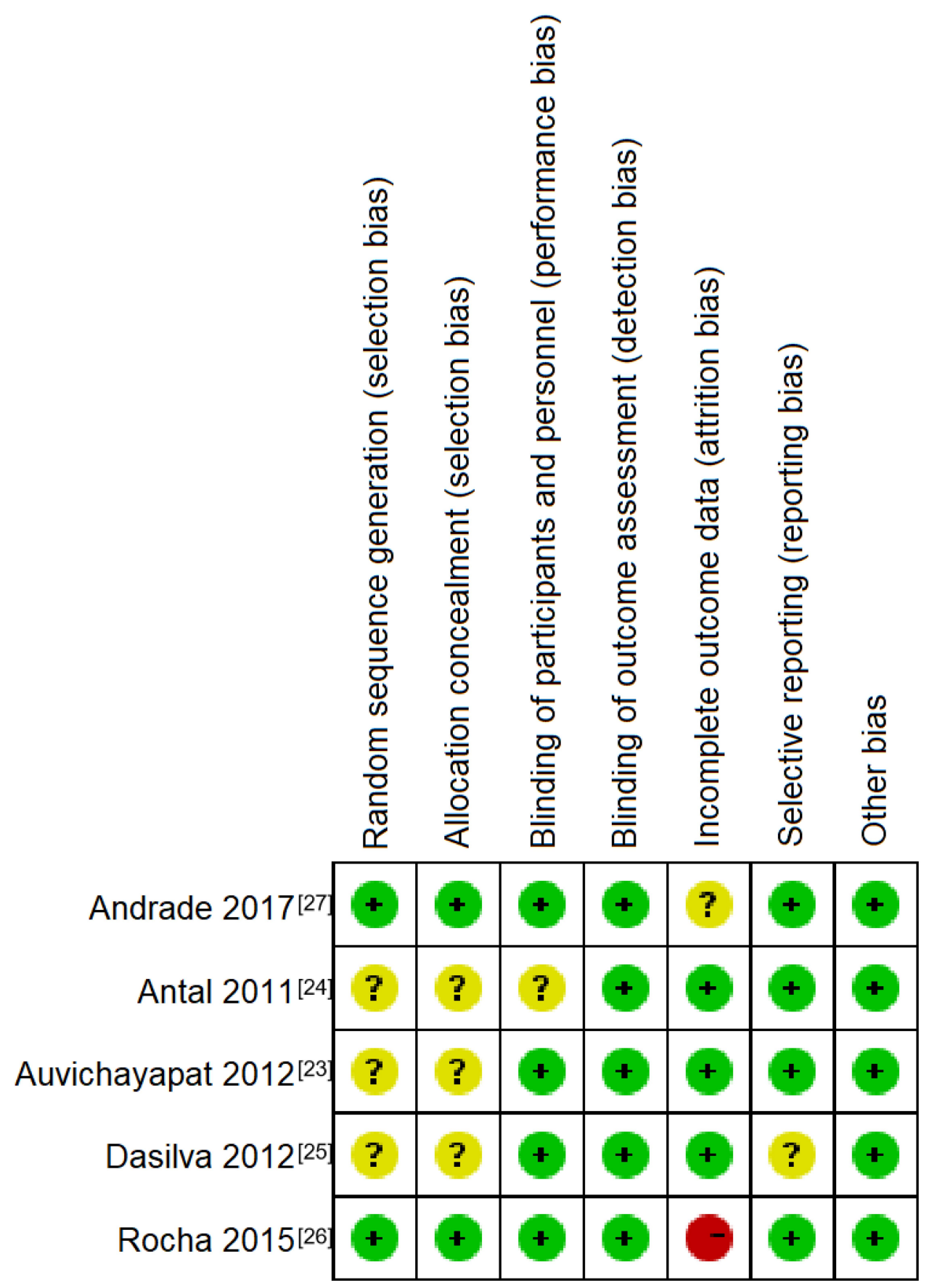

Figure 2 Risk of bias summary. Green "+“, red "“" and yellow "?"“ were used to classify the risk of bias of each criteria as: "low risk of bias", "high risk of bias" and "unclear".

\section{tDCS Protocols}

tDCS delivers mild electric current passed through two electrodes placed on the scalp to target the regions of interest, with positioning based on the international 10-20 EEG electrode placement system. The electrode montage varied in position across studies, including the L-M1 (C3), ${ }^{23,25,27} \mathrm{~L}-$ DLPFC (F3), ${ }^{27}$ and primary visual cortex $(\mathrm{Oz}){ }^{24,26}$ The reference electrode was placed away from the stimulation electrode, located at the contralateral superior orbital area (Fp2), ${ }^{23,25,27}$ or vertex (Cz). ${ }^{24,26}$ Three studies used anodal stimulation $^{23,25,27}$ and two studies used cathodal stimulation. ${ }^{24,26}$ One study used electrodes size of $5 * 5 \mathrm{~cm}^{27}$ and the others used that of $5 * 7 \mathrm{~cm}^{23-26}$ In all studies, the stimulation intensity of tDCS was between 1 2 mA.

tDCS effects are cumulative, with protocols administering daily or near-daily treatments of 15 to 20 minutes in 
duration. Baseline duration among studies ranged from 1 week to 8 weeks, treatment length varied from 4 weeks to 6 weeks, and follow-up duration ranged from 4 to 16 weeks. In addition, one study conducted electrophysiological studies before tDCS treatment, ${ }^{26}$ showing that tDCS can restore the abnormal visual cortical excitability in migraine patients. We summarized the included studies in Tables 1 and 2.

\section{Pain Intensity}

The active vs sham tDCS participants had significantly higher reduction of pain intensity. Based on a 10-point scale, the reduction of pain intensity in active group was 1.44 points more than that in sham group (MD: -1.44 , 95\% CI: $[-2.13,-0.76] ; \mathrm{P}<0.01$; Figure $3 \mathrm{~A}$ ).

Within the active tDCS participants, the pain intensity after treatment with tDCS stimulation was significantly lower than the baseline (after tDCS treatment (MD: $-1.86,95 \%$ CI: $[-3.30,-0.43]$; $\mathrm{P}=0.01$; Figure 3B). Significant reduction of pain intensity was also found in the long-term follow-up period (MD: $-1.52,95 \% \mathrm{CI}$ : $[-1.84,-1.20] ; \mathrm{P}<0.01)$. Further, we observed significant effects of both anodal (MD: $-1.74,95 \%$ CI: [-2.80, $-0.68] ; \mathrm{P}<0.01)$ and cathodal (MD: $-1.49,95 \% \mathrm{CI}$ : $[-1.89,-1.09] ; \mathrm{P}<0.01)$ stimulation on pain intensity (Figure 3C). In addition, the significant reduction was achieved by both $1 \mathrm{~mA}$ (MD: $-1.50,95 \%$ CI: [ -1.83 , $-1.17] ; \mathrm{P}<0.01)$ and $2 \mathrm{~mA}(\mathrm{MD}:-1.86,95 \% \mathrm{CI}:[-3.30$, -0.43 ]; $\mathrm{P}=0.01$; Figure 3D) current intensities (Figure 3D). Within the sham participants, we did not observe a significant difference after treatment compared to the baseline (Figure S1A) or between different types of stimulation (Figure S1B and $\underline{\mathrm{C}}$ ).

\section{Duration of Each Migraine Episode}

There was a trend in reduction of migraine duration (1.31 hrs) in the active vs sham tDCS participants. However, the reduction was not statistically significant (MD: -1.31 , 95\% CI: [-3.03, 0.41]; P=0.14; Figure 4A).

Within the active tDCS participants, a significant reduction was observed in migraine headache duration after treatment (MD: $-4.42,95 \%$ CI: [-8.11, -0.74$]$; $\mathrm{P}=0.02)$ and in follow-up period (MD: $-1.94,95 \% \mathrm{CI}$ : $[-3.10,-0.77] ; \mathrm{P}<0.01)$ as compared to the baseline (Figure 4B). Although not significant, we found a trend of reduction after applying cathodal stimulation (MD: $-2.61,95 \%$ CI: $[-5.29,0.08]$; $\mathrm{P}=0.06)$. In the only study which applied anodal stimulation, there was no reduction

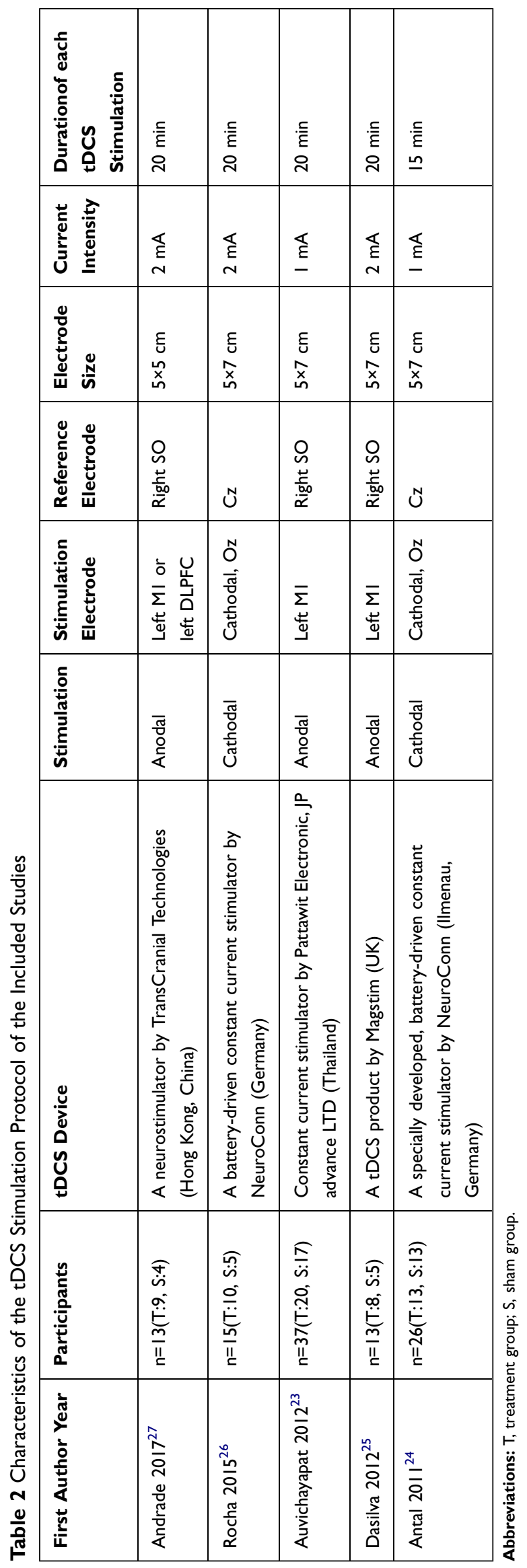




\begin{tabular}{|c|c|c|c|c|c|c|}
\hline \multirow[t]{2}{*}{$\mathbf{A}_{\underline{\text { study name }}}$} & \multicolumn{2}{|c|}{$\underline{\text { Sample size }}$} & \multicolumn{4}{|c|}{ Statistics for each study } \\
\hline & Active & Sham & $\begin{array}{l}\text { Difference } \\
\text { in means }\end{array}$ & $\begin{array}{c}\text { Lower } \\
\text { limit }\end{array}$ & $\begin{array}{l}\text { Upper } \\
\text { limit }\end{array}$ & p-Value \\
\hline Rocha et al. ${ }^{[26]}$ & 10 & 5 & -0.33 & -3.24 & 2.58 & 0.82 \\
\hline Antal et al. ${ }^{[24]}$ & 13 & 13 & -1.63 & -2.21 & -1.05 & 0.0 \\
\hline Auvichayapat et al al ${ }^{[23]}$ & 20 & 17 & -0.97 & -1.88 & -0.06 & 0.04 \\
\hline Andrade et al.M1 $1^{[27]}$ & 6 & 4 & -2.60 & -5.96 & 0.76 & 0.13 \\
\hline Andrade et al.DLPFC ${ }^{[27]}$ & 3 & 4 & -5.70 & -10.80 & -0.60 & 0.03 \\
\hline & & & -1.44 & -2.13 & -0.76 & 0.00 \\
\hline
\end{tabular}
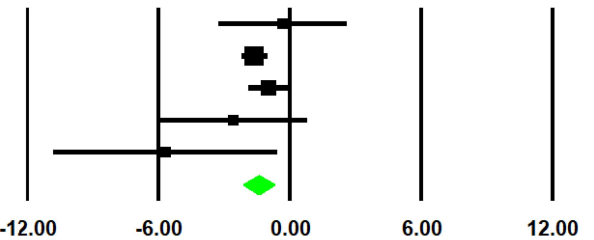

\begin{tabular}{|c|c|c|c|c|c|c|}
\hline \multirow{2}{*}{$\begin{array}{l}\text { Group by } \\
\text { Stage }\end{array}$} & \multirow[t]{2}{*}{ Study name } & \multicolumn{5}{|c|}{ Statistics for each study } \\
\hline & & Total & $\begin{array}{c}\text { Difference } \\
\text { in means }\end{array}$ & $\begin{array}{c}\text { Lower } \\
\text { limit }\end{array}$ & $\begin{array}{l}\text { Upper } \\
\text { limit }\end{array}$ & $\mathrm{p}$-Value \\
\hline after & Andrade et al.M1 $1^{[27]}$ & 6 & -3.10 & -5.71 & -0.49 & 0.02 \\
\hline after & Andrade et al.DLPFC ${ }^{[27]}$ & 3 & -6.20 & -12.12 & -0.28 & 0.04 \\
\hline after & Rocha et al. ${ }^{[26]}$ & 10 & -1.33 & -3.09 & 0.43 & 0.14 \\
\hline after & Dasilva et al. ${ }^{[25]}$ & 8 & -0.90 & -2.91 & 1.11 & 0.38 \\
\hline after & & & -1.86 & -3.30 & -0.43 & 0.01 \\
\hline follow-up & Rocha et al. ${ }^{[26]}$ & 10 & -2.33 & -4.49 & -0.17 & 0.03 \\
\hline follow-up & Dasilva et al. ${ }^{[25]}$ & 8 & -1.50 & -3.87 & 0.87 & 0.21 \\
\hline follow-up & Auvichayapat et al. ${ }^{[23]}$ & 20 & -1.50 & -2.05 & -0.95 & 0.00 \\
\hline follow-up & Antal et al. ${ }^{[24]}$ & 13 & -1.50 & -1.91 & -1.09 & 0.00 \\
\hline follow-up & & & -1.52 & -1.84 & -1.20 & 0.00 \\
\hline
\end{tabular}

\begin{tabular}{|c|c|c|c|c|c|c|}
\hline \multirow{2}{*}{$\begin{array}{l}\text { Group by } \\
\text { Group-stimulation }\end{array}$} & \multirow[t]{2}{*}{ Study name } & \multicolumn{5}{|c|}{ Statistics for each study } \\
\hline & & Total & $\begin{array}{l}\text { Difference } \\
\text { in means }\end{array}$ & $\begin{array}{c}\text { Lower } \\
\text { limit }\end{array}$ & $\begin{array}{l}\text { Upper } \\
\text { limit }\end{array}$ & p-Value \\
\hline anodal & Andrade et al.M1 ${ }^{[27]}$ & 6 & -3.10 & -5.71 & -0.49 & 0.0 \\
\hline anodal & Andrade et al.DLPFC ${ }^{[27]}$ & 3 & -6.20 & -12.12 & -0.28 & 0.0 \\
\hline anodal & Dasilva et al. ${ }^{[25]}$ & 8 & -0.90 & -2.91 & 1.11 & 0. \\
\hline anodal & Auvichayapat et al. ${ }^{[23]}$ & 20 & -1.50 & -2.05 & -0.95 & 0.00 \\
\hline anodal & & & -1.74 & -2.80 & -0.68 & 0.00 \\
\hline cathodal & Rocha et al. ${ }^{[26]}$ & 10 & -1.33 & -3.09 & 0.43 & 0.14 \\
\hline cathodal & Antal et al. ${ }^{[24]}$ & 13 & -1.50 & -1.91 & -1.09 & 0.00 \\
\hline cathodal & & & -1.49 & -1.89 & -1.09 & 0.00 \\
\hline
\end{tabular}

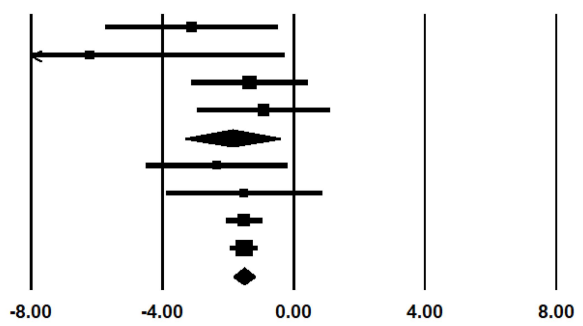

\begin{tabular}{|c|c|c|c|c|c|c|}
\hline \multirow{2}{*}{$\begin{array}{l}\text { Group by } \\
\text { Current intensity }\end{array}$} & \multirow[t]{2}{*}{ Study name } & \multicolumn{5}{|c|}{ Statistics for each study } \\
\hline & & Total & $\begin{array}{l}\text { Difference } \\
\text { in means }\end{array}$ & $\begin{array}{l}\text { Lower } \\
\text { limit }\end{array}$ & $\begin{array}{l}\text { Upper } \\
\text { limit }\end{array}$ & $\mathrm{p}$-Value \\
\hline $1 \mathrm{~mA}$ & Auvichayapat et al. ${ }^{[23]}$ & 20 & -1.50 & -2.05 & -0.95 & 0.00 \\
\hline $1 \mathrm{~mA}$ & Antal et al. ${ }^{[24]}$ & 13 & -1.50 & -1.91 & -1.09 & 0.00 \\
\hline $1 \mathrm{~mA}$ & & & -1.50 & -1.83 & -1.17 & 0.00 \\
\hline $2 \mathrm{~mA}$ & Andrade et al.M1 ${ }^{[27]}$ & 6 & -3.10 & -5.71 & -0.49 & 0.02 \\
\hline $2 \mathrm{~mA}$ & Andrade et al.DLPFC ${ }^{[27]}$ & 3 & -6.20 & -12.12 & -0.28 & 0.04 \\
\hline $2 \mathrm{~mA}$ & Rocha et al. ${ }^{[26]}$ & 10 & -1.33 & -3.09 & 0.43 & 0.14 \\
\hline $2 \mathrm{~mA}$ & Dasilva et al. ${ }^{[25]}$ & 8 & -0.90 & -2.91 & 1.11 & 0.38 \\
\hline $2 \mathrm{~mA}$ & & & -1.86 & -3.30 & -0.43 & 0.01 \\
\hline
\end{tabular}
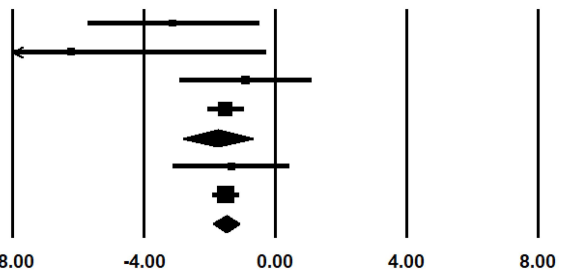

Figure 3 Pain intensity Meta-analysis in treatment group. (A) Between group analysis; (B) after versus baseline and follow-up versus baseline; (C) subgroup analysis considering type of stimulation; (D) subgroup analysis considering current intensity.

in migraine duration (MD: $-3.00 ; 95 \%$ CI: $[-11.04,5.04] ; \quad-4.42,95 \%$ CI: $[-8.11,-0.74] ; \mathrm{P}=0.02$ ) current intensities $\mathrm{P}=0.46$ ) (Figure $4 \mathrm{C}$ ). Both treatments with $1 \mathrm{~mA}$ (MD: $-1.75,95 \% \mathrm{CI}$ : $[-2.98,-0.52] ; \mathrm{P}=0.01)$ and $2 \mathrm{~mA}$ (MD: Within the sham participants, there was no significant 


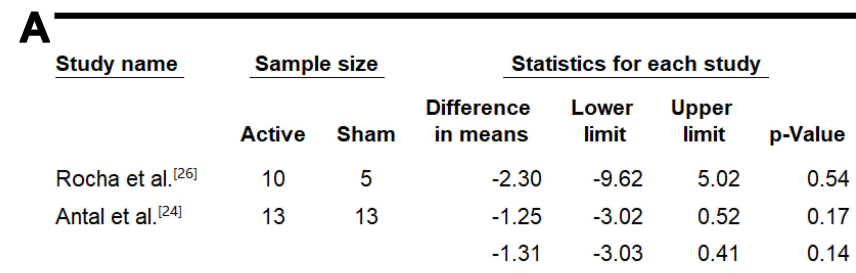

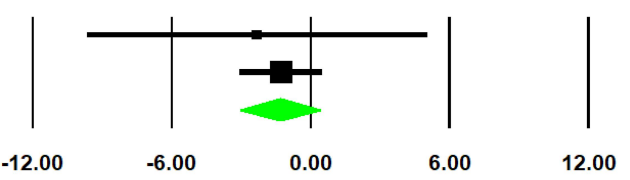

\begin{tabular}{|c|c|c|c|c|c|c|}
\hline \multirow{2}{*}{$\begin{array}{l}\text { Group by } \\
\text { Stage }\end{array}$} & \multirow[t]{2}{*}{ Study name } & \multirow[b]{2}{*}{ Total } & \multicolumn{3}{|c|}{ Statistics for each study } & \multirow[b]{2}{*}{$p$-Value } \\
\hline & & & $\begin{array}{l}\text { Difference } \\
\text { in means }\end{array}$ & $\begin{array}{c}\text { Lower } \\
\text { limit }\end{array}$ & $\begin{array}{l}\text { Upper } \\
\text { limit }\end{array}$ & \\
\hline after & Rocha et al. ${ }^{[26]}$ & 10 & -4.80 & -8.95 & -0.65 & 0.02 \\
\hline after & Dasilva et al. ${ }^{[25]}$ & 8 & -3.00 & -11.04 & 5.04 & 0.46 \\
\hline after & & & -4.42 & -8.11 & -0.74 & 0.02 \\
\hline follow-up & Rocha et al. ${ }^{[26]}$ & 10 & -3.70 & -8.13 & 0.73 & 0.10 \\
\hline follow-up & Dasilva et al. ${ }^{[25]}$ & 8 & -3.70 & -11.07 & 3.67 & 0.33 \\
\hline follow-up & Antal et al. ${ }^{[24]}$ & 13 & -1.75 & -2.98 & -0.52 & 0.01 \\
\hline follow-up & & & -1.94 & -3.10 & -0.77 & 0.00 \\
\hline
\end{tabular}

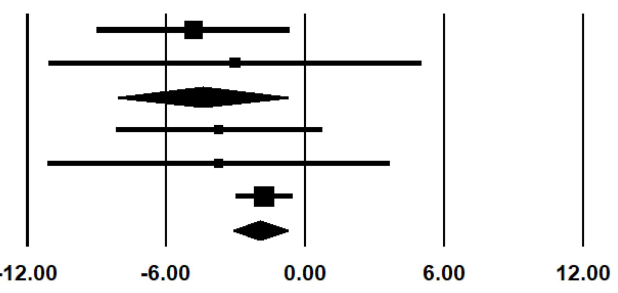

\begin{tabular}{|c|c|c|c|c|c|c|}
\hline \multirow{2}{*}{$\begin{array}{l}\text { Group by } \\
\text { Group-stimulation }\end{array}$} & \multirow[t]{2}{*}{ Study name } & \multirow[b]{2}{*}{ Total } & \multicolumn{4}{|c|}{ Statistics for each study } \\
\hline & & & $\begin{array}{l}\text { Difference } \\
\text { in means }\end{array}$ & $\begin{array}{l}\text { Lower } \\
\text { limit }\end{array}$ & $\begin{array}{l}\text { Upper } \\
\text { limit }\end{array}$ & $\mathrm{p}$-Value \\
\hline anodal & Dasilva et al. ${ }^{[25]}$ & 8 & -3.00 & -11.04 & 5.04 & 0.46 \\
\hline anodal & & & -3.00 & -11.04 & 5.04 & 0.46 \\
\hline cathodal & Rocha et al. ${ }^{[26]}$ & 10 & -4.80 & -8.95 & -0.65 & 0.02 \\
\hline cathodal & Antal et al. ${ }^{[24]}$ & 13 & -1.75 & -2.98 & -0.52 & 0.01 \\
\hline cathodal & & & -2.61 & -5.29 & 0.08 & 0.06 \\
\hline
\end{tabular}
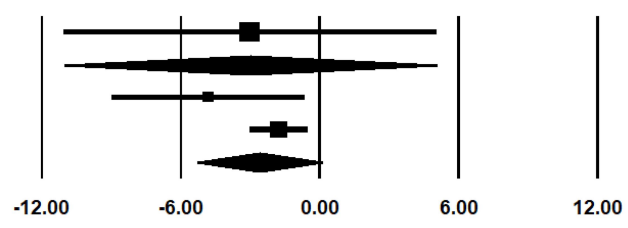

\begin{tabular}{|c|c|c|c|c|c|c|}
\hline \multirow{2}{*}{$\begin{array}{l}\text { Group by } \\
\text { Current intensity }\end{array}$} & \multirow[t]{2}{*}{ Study name } & \multicolumn{4}{|c|}{ Statistics for each study } & \multirow[b]{2}{*}{ p-Value } \\
\hline & & Total & $\begin{array}{c}\text { Difference } \\
\text { in means }\end{array}$ & $\begin{array}{l}\text { Lower } \\
\text { limit }\end{array}$ & $\begin{array}{l}\text { Upper } \\
\text { limit }\end{array}$ & \\
\hline $1 \mathrm{~mA}$ & Antal et al. ${ }^{[24]}$ & 13 & -1.75 & -2.98 & -0.52 & 0.01 \\
\hline $1 \mathrm{~mA}$ & & & -1.75 & -2.98 & -0.52 & 0.01 \\
\hline $2 \mathrm{~mA}$ & Rocha et al. ${ }^{[26]}$ & 10 & -4.80 & -8.95 & -0.65 & 0.02 \\
\hline $2 \mathrm{~mA}$ & Dasilva et al. ${ }^{[25]}$ & 8 & -3.00 & -11.04 & 5.04 & 0.46 \\
\hline $2 \mathrm{~mA}$ & & & -4.42 & -8.11 & -0.74 & 0.02 \\
\hline
\end{tabular}
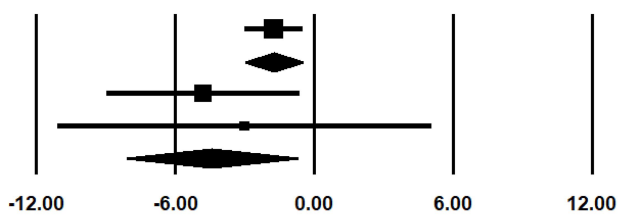

Figure 4 Duration of migraine episode Meta-analysis in treatment group. (A) Between group analysis; (B) after versus baseline and follow-up versus baseline; (C) subgroup analysis considering type of stimulation; (D) subgroup analysis considering current intensity.

effect on the duration of headache episode after treatment or in the follow-up period (Figure S2A) using cathodal stimulation (Figure S2B) or anodal stimulation at different current intensities ( $\underline{\text { Figure S2C)}}$.

\section{Other Outcomes}

Additionally, we performed a narrative review on tDCS efficacy in terms of migraine days per month, number of migraine attacks per month, and the use of pain 
medications. Not all studies reported these outcome measures and therefore we did not perform meta-analysis. We summarized the reported results of these studies in Table 3. Using the data from the original studies, we tested the differences of each outcome measurement in active vs sham tDCS treatment participants by accounting the difference in the baseline assessment (see Methods).

\section{Migraine Days per Month}

Only one study ${ }^{24}$ meet our eligibility criteria in evaluating migraine frequency. This study found a significant reduction in migraine-related days after stimulation in the active tDCS group ( $\mathrm{p}=0.004)$ but not in the sham group $(\mathrm{p}=0.17)$. While the original study did not find a significant difference between active and sham participants $(\mathrm{p}=0.61)$, the investigators had not accounted for the migraine frequency difference between the groups in the baseline. Our re-analysis found that headache frequency improved in the active vs sham tDCS participants by 3.45 days $(\mathrm{p}=0.001)$.

\section{Number of Migraine Attacks per Month}

Although three studies ${ }^{23,24,26}$ investigated the efficacy of tDCS on monthly migraine attacks, Antal et al did not report raw values (only the $\mathrm{p}$ values). When comparing to

Table 3 tDCs on Migraine Days per Month, Number of Migraine Attacks and the Use of Pain Medications

\begin{tabular}{|c|c|c|c|c|}
\hline Study & Comparison & Mean $\pm S D$ & Mean士SD & p-value \\
\hline \multicolumn{5}{|c|}{ Migraine Days Per Month } \\
\hline \multirow[t]{4}{*}{ Antal, $201 \mathrm{I}^{24}$} & Follow-up versus baseline in active group & Baseline $8.10 \pm 1.20$ & Follow-up $4.66 \pm 0.75$ & 0.004 \\
\hline & Follow-up versus baseline in sham group & Baseline $6.40 \pm 1.39$ & Follow-up $5.50 \pm \mathrm{I} .75$ & 0.17 \\
\hline & Original study, active tDCS versus sham & Follow-up $4.66 \pm 0.75$ & Follow-up $5.50 \pm \mathrm{I} .75$ & 0.61 \\
\hline & Our analysis, active tDCS versus sham & $-3.45 \pm 1.42$ & $-0.90 \pm 2.23$ & 0.001 \\
\hline \multicolumn{5}{|c|}{ Number of Migraine Attacks } \\
\hline \multirow[t]{7}{*}{ Rocha, $2015^{26}$} & After last stimulation versus baseline in active group & Baseline $7.30 \pm 4.70$ & After last stimulation $6.30 \pm 5.00$ & 0.242 \\
\hline & Follow-up versus baseline in active group & Baseline $7.30 \pm 4.70$ & Follow-up $3.90 \pm 2.90$ & 0.027 \\
\hline & After last stimulation versus baseline in sham group & Baseline $14.70 \pm 13.60$ & After laststimulation II. $30 \pm 7.60$ & Not available \\
\hline & Follow-up versus baseline in sham group & Baseline $14.70 \pm 13.60$ & Follow-up $9.00 \pm 10.40$ & Not available \\
\hline & Original study, active tDCS versus sham & Not available & Not available & Not available \\
\hline & Our analysis, active versus sham & $-1.00 \pm 6.86$ & $-3.40 \pm 15.58$ & 0.672 \\
\hline & Our analysis, active versus sham follow-up & $-3.40 \pm 5.52$ & $-5.70 \pm 17.12$ & 0.691 \\
\hline \multirow[t]{4}{*}{ Auvichayapat, $2012^{23}$} & Follow-up versus baseline in active group & Baseline $3.85 \pm 0.88$ & Follow-up $2.80 \pm 0.69$ & $<0.01$ \\
\hline & Follow-up versus baseline in sham group & Baseline $3.76 \pm 0.90$ & Follow-up $3.7 \mathrm{I} \pm 0.92$ & 0.33 \\
\hline & Original study, active tDCS versus sham & Not available & Not available & Not available \\
\hline & Our analysis, active versus sham & $-1.05 \pm 1.12$ & $-0.05 \pm 1.29$ & 0.012 \\
\hline \multirow[t]{4}{*}{ Antal, $201 \mathrm{I}^{24}$} & Follow-up versus baseline in active group & Not available & Not available & 0.38 \\
\hline & Follow-up versus baseline in sham group & Not available & Not available & 0.2 \\
\hline & Original study, active tDCS versus sham & Not available & Not available & 0.88 \\
\hline & Our analysis, active versus sham & Not available & Not available & Not available \\
\hline \multicolumn{5}{|c|}{ Use of Pain Medications } \\
\hline \multirow[t]{7}{*}{ Rocha, $2015^{26}$} & After last stimulation versus baseline in active group & Baseline $3.70 \pm 2.20$ & After laststimulation $1.70 \pm 1.90$ & 0.026 \\
\hline & Follow-up versus baseline in active group & Baseline $3.70 \pm 2.20$ & Follow-up $1.60 \pm 1.10$ & 0.05 \\
\hline & After last stimulation versus baseline in sham group & Baseline $12.7 \pm 15.1$ & After laststimulation $8.70 \pm 10.00$ & Not available \\
\hline & Follow-up versus baseline in sham group & Baseline $12.7 \pm|5|$. & Follow-up $8.70 \pm 10.70$ & Not available \\
\hline & Original study, active tDCS versus sham & Not available & Not available & Not available \\
\hline & Our analysis, active versus sham & $-2.00 \pm 2.91$ & $-4.00 \pm 18.11$ & 0.724 \\
\hline & Our analysis, active versus sham follow-up & $-2.10 \pm 2.46$ & $-4.00 \pm|8.5|$ & 0.74 \\
\hline \multirow[t]{4}{*}{ Auvichayapat, $2012^{23}$} & Follow-up versus baseline in active group & Baseline $19.40 \pm 2.62$ & Follow-up $14.00 \pm 3.60$ & $<0.01$ \\
\hline & Follow-up versus baseline in sham group & Baseline $20.65 \pm 3.59$ & Follow-up $16.80 \pm 3.90$ & $<0.01$ \\
\hline & Original study, active tDCS versus sham & Not available & Not available & Not available \\
\hline & Our analysis, active versus sham & $-5.40 \pm 4.45$ & $-3.85 \pm 5.30$ & 0.333 \\
\hline
\end{tabular}

Note: $\mathrm{p}$-values less than 0.05 were shown in bold. 
the sham group, the data from Auvichayapat et $\mathrm{al}^{23}$ showed a significant reduction of the number of migraine attacks in the active tDCs group $(p=0.012)$. We did not observe a significant reduction in Rocha et $\mathrm{al}^{26}$ study.

Within the active tDCS group, two studies ${ }^{23,26}$ found that attack frequency was significant decreased in the follow-up period when compared to baseline, while the study of Antal et al found no significant difference. ${ }^{24}$ No statistically significant reduction was found within the sham group.

\section{Use of Pain Medications}

We reviewed two studies ${ }^{23,26}$ and found no difference on the use of pain medications when comparing to active tDCS to sham group. However, active tDCS was associated with a statistically significant reduction in use ofabortive medications, including ergotamine, ibuprofen, acetaminophen, triptans, paracetamol, and others as compared to baseline. Notably, Auvichayapat et $\mathrm{al}^{23}$ showed a statistically significant reduction in the use of abortive medications in a follow-up period $(\mathrm{p}<0.01)$. Our further review found a significantly higher intake of pain medication at baseline in sham group (12.7 \pm 15.1 tablets) compared to the tDCS treatment group (3.7 \pm 2.2 tablets) in that study. ${ }^{26}$ After adjusting the difference in the baseline, we did not find a significant reduction in pain medications use in the active tDCS versus sham participants.

\section{Discussion}

There is a growing body of literature addressing the use of tDCS for the management of migraine but very few studies have evaluated repeated tDCS stimulation treatments spanning 4 weeks or longer. Combining across variations in tDCS parameters including polarity, montage, and stimulation intensity between 1-2 mA, we found that repetitive active tDCS stimulation resulted in significant reduction of pain intensity in migraine as compared to sham stimulation. We also observed a trend for reduction in the duration of migraine episode. Based on literature review, we also found migraine days per month and number of migraine attacks could be improved.

Our results suggest that there is a long-term sustained benefit of repetitive tDCS at least 4 weeks. The results from a meta-analysis in $2016^{16}$ were consistent with our findings in terms of the reduction of pain intensity and number of migraine attacks. However, we did not find a significant decrease for pain medication intake as reported in their meta-analysis. Further evaluation found that the previous analysis misused the duration of each migraine attack as the number of pain medication intake (data extracted from Rocha's study ${ }^{26}$ ), leading to an erroneous conclusion that pain medication use was decreased after tDCS. Additionally, there is a significant mismatch of the pain medication intake at baseline between sham group and the tDCS treatment group in Rocha's study. ${ }^{26}$ Future studies with larger sample sizes and matched group assignment are needed for validation.

Stimulation parameters, such as stimulation polarity, electrode montage, duration of each session, number of sessions, and current intensity are selected to achieve the desired therapeutic effect of tDCS. ${ }^{28}$ At present, the 10/20 electroencephalography (EEG) electrode placement system is usually used to guide the montage for the placement of tDCS anode and cathode electrodes using a variety of stimulation protocols. ${ }^{29}$ In general, anodal stimulation is presumed to result in depolarization whereas cathodal stimulation results in hyperpolarization. ${ }^{11}$ However, stimulation of either polarity may have both depolarizing and/or hyperpolarizing effects. For example, anodal and cathodal tDCS applied to Wernicke's area improved semantic processing compared to sham stimulation in healthy subjects. ${ }^{30}$ In patients with stroke, anodal stimulation improved manual dexterity and cathodal stimulation seemed to have some benefit for force improvement. ${ }^{31}$

In our meta-analysis, both anodal and cathodal stimulation were significantly effective in the reducing pain intensity. Importantly, studies with cathodal stimulation targeted the occipital region while studies using anodal stimulation targeted M1 or DLFPC. Our finding is consistent with polarity to be dependent on the targeted region for therapeutic effect. Both occipital cathodal stimulation and anodal primary motor stimulation were selected in the respective studies based on the current understanding of pathophysiology of migraine. With at least two potential regional targets, future studies should be designed to compare montages to determine optimal treatment effects.

Depending on the montage configurations, the electrical field generated via tDCS generally spreads to nearby cortical and subcortical structures. ${ }^{10}$ Duration of electrical changes is typically maintained only for an hour locally after one time tDCS treatment, ${ }^{11}$ while sustained and repeated tDCS sessions can provoke cumulative and long-lasting neuroplastic changes in the cerebral cortex. ${ }^{12}$ Even though the majority of current clinical trials using tDCS for a variety of neurological disorders have been limited by the number of sessions (many studies report 
findings after 10 or less daily sessions), those that have used extended designs have demonstrated cumulative behavioral $^{13,14}$ and motor ${ }^{15}$ effects. Recently, tDCS studies have been performed with an increased diversity of montages. Yet, no standard is available for montage configuration. ${ }^{32}$ Some researchers have suggested that the efficacy of tDCS in chronic migraine is dependent on individualized montage design guided by thermography, which can be customized to each single patient. ${ }^{33}$

In terms of study design, assessment of migrainerelated disability as one of the outcomes in tDCS clinical trials is necessary to fully evaluate the efficacy of tDCS on migraine. In our review, most of the studies did not consider the impact of tDCS on migraine-related disability. Only in one study, HIT-6 and SF-36 were used. This study did report an improvement in HIT-6 and quality of life after tDCS. ${ }^{27}$ Pinchuk et al measured the level of state anxiety and trait anxiety, which significantly decreased after tDCS treatment. ${ }^{34}$ Additionally, the assessment of pain control in migraine patients is a subjective self-evaluation, which may change due to hormonal influence and their own ethnic and cultural differences. ${ }^{35}$ However, if data collection during baseline and other endpoints is completed for at least four to five weeks (one menstrual cycle), hormonal influence may be minimized. Therefore, baseline period of at least 4 weeks is necessary when evaluating tDCS benefit in migraine. Lastly, it may be helpful to perform subgroup analyses to compare treatment response in men and women separately.

Future clinical trials using tDCS in migraine may include administering tDCS while simultaneously measuring neuronal activity using EEG or fMRI to better understand the underlying mechanism of action. High-definition transcranial direct current stimulation (HD-tDCS), which can provide more focal stimulation in selected brain regions, ${ }^{36,37}$ is effective in facilitating the rate of verbal learning and working memory in healthy subjects ${ }^{38}$ and aphasia recovery in patients with stroke. ${ }^{39}$ However, HDtDCS does not have the advantage of remote administration at home via telehealth, which can be done using standard tDCS. In addition, the combination of tDCS with other non-pharmacological therapy for migraine may provide synergy and long-term effects.

Our meta-analysis study has some limitations. First, our analyses did not include studies with insufficient data, such as the study of Wickmann et $\mathrm{al}^{40}$ which only reported p-values, but their results supported our conclusion. Second, we rescaled pain intensity in some studies, which led to an estimated assessment. Furthermore, the heterogeneity of these studies and small sample sizes limit our conclusion to a certain extent.

\section{Acknowledgment}

We thank Dr. Karen Chen for her assistance in editing the manuscript.

This article does not contain any studies with human or animal subjects performed by any of the authors. The contents of this paper do not represent the views of the US Department of Veterans Affairs or the United States Government.

\section{Disclosure}

The authors report no conflicts of interest in this work.

\section{References}

1. World Health Organization. Neurological disorders: public health challenges - World Health Organization [Internet]. WHO press; 2006:140-150.

2. Feigin VL, Krishnamurthi RV, Theadom AM, et al. Global, regional, and national burden of neurological disorders during 1990-2015: a systematic analysis for the Global Burden of Disease Study 2015. Lancet Neurol. 2017;16(11):877-897. doi:10.1016/S1474-4422(17)30299-5

3. Steiner TJ, Stovner LJ, Birbeck GL. Migraine: the seventh disabler. $J$ Headache Pain. 2013;14:1. doi:10.1186/1129-2377-14-1

4. Olesen J, Bes A, Kunkel R, et al. The international classification of headache disorders, 3rd edition (beta version). Cephalalgia. 2013;33 (9):629-808.

5. Dodick DW. A phase-by-phase review of migraine pathophysiology. Headache. 2018;1(58):4-16. doi:10.1111/head.13300

6. Dodick DW. Migraine. The Lancet. 2018;391:1315-1330. doi:10.10 16/S0140-6736(18)30478-1

7. Maasumi K, Michael RL, Rapoport AM. CGRP and migraine: the role of blocking calcitonin gene-related peptide ligand and receptor in the management of migraine. Drugs. 2018;78:913-928. doi:10.1007/ s40265-018-0923-5

8. Whyte CA, Tepper SJ. Adverse effects of medications commonly used in the treatment of migraine. Expert Rev Neurother. 2009;9:1379-1391. doi:10.1586/ern.09.47

9. Viganò A, Toscano M, Puledda F, Di Piero V. Treating chronic migraine with neuromodulation: the role of neurophysiological abnormalities and maladaptive plasticity. Front Pharmacol. 2019;10 (FEB). doi:10.3389/fphar.2019.00032

10. Bikson M, Rahman A. Origins of specificity during tDCS: anatomical, activity-selective, and input-bias mechanisms. Front Hum Neurosci. 2013. doi:10.3389/fnhum.2013.00688

11. Nitsche MA, Paulus W. Excitability changes induced in the human motor cortex by weak transcranial direct current stimulation. $J$ Physiol. 2000;527(3):633-639. doi:10.1111/j.1469-7793.2000.t01-1-00633.x

12. Monte-Silva K, Kuo MF, Hessenthaler S, et al. Induction of late LTPlike plasticity in the human motor cortex by repeated non-invasive brain stimulation. Brain Stimul. 2013;6(3):424-432. doi:10.1016/j. brs.2012.04.011

13. Fregni F, Boggio PS, Nitsche MA, Rigonatti SP, Pascual-Leone A. Cognitive effects of repeated sessions of transcranial direct current stimulation in patients with depression. Depress Anxiety. 2006; 23:482-484. doi:10.1002/da.20201 
14. Nikolin S, Huggins C, Martin D, Alonzo A, Loo CK. Safety of repeated sessions of transcranial direct current stimulation: a systematic review. Brain Stimul. 2018;11(2):278-288. doi:10.1016/j. brs.2017.10.020

15. Boggio PS, Nunes A, Rigonatti SP, Nitsche MA, Pascual-Leone A, Fregni F. Repeated sessions of noninvasive brain DC stimulation is associated with motor function improvement in stroke patients. Restor Neurol Neurosci. 2007;25(2):123-129.

16. Shirahige L, Melo L, Nogueira F, Rocha S, Monte-Silva K. Efficacy of noninvasive brain stimulation on pain control in migraine patients: a systematic review and meta-analysis. Headache. 2016;56 (10):1565-1596. doi:10.1111/head.12981

17. Feng Y, Zhang B, Zhang J, Yin Y. Effects of non-invasive brain stimulation on headache intensity and frequency of headache attacks in patients with migraine: a systematic review and meta-analysis. Headache. 2019;59(9):1436-1447. doi:10.1111/head.13645

18. Kobayashi M, Pascual-Leone A. Transcranial magnetic stimulation in neurology. Lancet Neurol. 2003;2:145-156. doi:10.1016/S1474-4422 (03)00321-1

19. Moher D, Liberati A, Tetzlaff J, et al. Preferred reporting items for systematic reviews and meta-analyses: the PRISMA statement. PLoS Med. 2009;6:e1000097. doi:10.1371/journal.pmed.1000097

20. Huang X, Lin J, Demner-Fushman D. Evaluation of PICO as a knowledge representation for clinical questions. AMIA Annu Symp Proc. 2006;2006:359-363.

21. Higgins JPT, Altman DG, Gøtzsche PC, et al. The cochrane collaboration's tool for assessing risk of bias in randomised trials. BMJ 2011;343(7829):d5928-d5928. doi:10.1136/bmj.d5928

22. Higgins JP, Julian PT, Green S. Cochrane handbook for systematic reviews of interventions [Internet]. 2019:649.

23. Auvichayapat P, Janyacharoen T, Rotenberg A, et al. Migraine prophylaxis by anodal transcranial direct current stimulation, a randomized, placebo-controlled trial. J Med Assoc Thail. 2012;95(8):10091012

24. Antal A, Kriener N, Lang N, Boros K, Paulus W. Cathodal transcranial direct current stimulation of the visual cortex in the prophylactic treatment of migraine. Cephalalgia. 2011;31(7):820-828. doi:10.11 77/0333102411399349

25. Dasilva AF, Mendonca ME, Zaghi S, et al. TDCS-induced analgesia and electrical fields in pain-related neural networks in chronic migraine. Headache. 2012;52(8):1283-1295. doi:10.1111/j.15264610.2012.02141.x

26. Rocha S, Melo L, Boudoux C, Foerster Á, Araújo D, Monte-Silva K. Transcranial direct current stimulation in the prophylactic treatment of migraine based on interictal visual cortex excitability abnormalities: a pilot randomized controlled trial. J Neurol Sci. 2015;349(12):33-39. doi:10.1016/j.jns.2014.12.018

27. Andrade SM, de Brito Aranha REL, de Oliveira EA, et al. Transcranial direct current stimulation over the primary motor vs prefrontal cortex in refractory chronic migraine: a pilot randomized controlled trial. J Neurol Sci. 2017;378:225-232. doi:10.1016/j. jns.2017.05.007
28. Batsikadze G, Moliadze V, Paulus W, Kuo MF, Nitsche MA. Partially non-linear stimulation intensity-dependent effects of direct current stimulation on motor cortex excitability in humans. $J$ Physiol. 2013;591(7):1987-2000. doi:10.1113/jphysiol.2012.249730

29. Rich TL, Gillick BT. Electrode placement in transcranial direct current stimulation-how reliable is the determination of $\mathrm{C} 3 / \mathrm{C} 4$ ? Brain Sci. 2019;9(3):69. doi:10.3390/brainsci9030069

30. Brückner S, Kammer T. Both anodal and cathodal transcranial direct current stimulation improves semantic processing. Neuroscience. 2017;20(343):269-275. doi:10.1016/j.neuroscience.2016.12.015

31. Fusco A, De Angelis D, Morone G, et al. The ABC of tDCS: effects of anodal, bilateral and cathodal montages of transcranial direct current stimulation in patients with stroke - A pilot study. Stroke Res Treat. 2013;2013. doi:10.1155/2013/837595

32. Nasseri P, Nitsche MA, Ekhtiari H. A framework for categorizing electrode montages in transcranial direct current stimulation. Front Hum Neurosci. 2015;9(FEB). doi:10.3389/fnhum.2015.00054

33. Dalla Volta G, Marceglia S, Zavarise P, Antonaci F. Cathodal tDCS guided by thermography as adjunctive therapy in chronic migraine patients: a sham-controlled pilot study. Front Neurol. 2020;11. doi:10.3389/fneur.2020.00121

34. Pinchuk D, Pinchuk O, Sirbiladze K, Shugar O. Clinical effectiveness of primary and secondary headache treatment by transcranial direct current stimulation. Front Neurol. 2013;4:25. doi:10.3389/fneur.20 13.00025

35. Fillingim RB, King CD, Ribeiro-Dasilva MC, Rahim-Williams B, Riley JL. Sex, gender, and pain: a review of recent clinical and experimental findings [Internet]. J Pain. 2009; 10:447-485.

36. DaSilva AF, Truong DQ, DosSantos MF, Toback RL, Datta A, Bikson M. State-of-art neuroanatomical target analysis of high-definition and conventional tDCS montages used for migraine and pain control. Front Neuroanat. 2015;9:1-12. doi:10.3389/fnana.2015.00 089

37. Donnell A, Nascimento TD, Lawrence M, et al. High-definition and non-invasive brain modulation of pain and motor dysfunction in chronic TMD. Brain Stimul. 2015;8(6):1085-1092. doi:10.1016/j. brs.2015.06.008

38. Nikolin S, Loo CK, Bai S, Dokos S, Martin DM. Focalised stimulation using high definition transcranial direct current stimulation (HDtDCS) to investigate declarative verbal learning and memory functioning. Neuroimage. 2015;117:11-19. doi:10.1016/j.neuroimage.20 15.05 .019

39. Richardson J, Datta A, Dmochowski J, Parra LC, Fridriksson J. Feasibility of using high-definition transcranial direct current stimulation (HD-tDCS) to enhance treatment outcomes in persons with aphasia. NeuroRehabilitation. 2015;36(1):115-126. doi:10.3233/ NRE-141199

40. Wickmann F, Stephani C, Czesnik D, et al. Prophylactic treatment in menstrual migraine: a proof-of-concept study. J Neurol Sci. 2015;354 (1-2):103-109. doi:10.1016/j.jns.2015.05.009
Journal of Pain Research

\section{Publish your work in this journal}

The Journal of Pain Research is an international, peer reviewed, open access, online journal that welcomes laboratory and clinical findings in the fields of pain research and the prevention and management of pain. Original research, reviews, symposium reports, hypothesis formation and commentaries are all considered for publication. The manuscript

Submit your manuscript here: https://www.dovepress.com/journal-of-pain-research-journal management system is completely online and includes a very quick and fair peer-review system, which is all easy to use. Visit http:// www.dovepress.com/testimonials.php to read real quotes from published authors. 